\title{
Extensão universitária e Projeto Rondon: o papel da universidade no desenvolvimento social
}

\author{
University extension and Rondon Project: the role of university in social development
}

Proyecto de extensión universitaria y Rondon: el papel de la universidad en el desarrollo social

\section{Resumo}

Recém declarado como Patrimônio Imaterial da Educação Superior Brasileira, pelo Projeto de Lei no 4613 de 2019 , Projeto Rondon, desenvolvido pelo Ministério da Defesa, em parceria com governos estaduais, municipais e Instituições de Ensino Superior (IES) públicas e privadas, tem como objetivo contribuir para a formação do jovem universitário como cidadão e o desenvolvimento sustentável em comunidades pouco assistidas. Neste sentido, o presente trabalho relata a experiência de discentes e docentes da Universidade José do Rosário Vellano- UNIFENAS, campus Alfenas, resultante da participação na Operação Vale do Acre desenvolvidas entre os dias 08 e 17 de julho de 2019, na cidade de Acrelândia-AC. Foram realizadas 29 oficinas, com temáticas relacionadas a Comunicação, Trabalho e Produção, Meio Ambiente e Tecnologia, sendo capacitadas 2.148 pessoas, destacando a participação de crianças, adolescentes - jovens, adultos e idosos, além da participação em massa por parte da população rural, com predomínio do sexo feminino.

Palavras-chave: Projeto rondon; Extensão universitária; Meio ambiente; Educação; Comunicação.

\section{Abstract}

Recently declared as Intangible Heritage of Brazilian Higher Education, by Law Project No. 4613 of 2019, the Rondon Project, developed by the Ministry of Defense, in partnership with state, municipal and public and private Higher Education Institutions (IES), the objective is to contribute to the formation of the university students as 
citizens and sustainable development in poorly assisted communities. In this sense, the present work reports the experience of students and professors of the University of José do Rosário Vellano-UNIFENAS, Alfenas campus, resulting from the participation in Operation Vale do Acre developed between July 08-17, 2019, in the city of Acrelândia-AC. Twenty-nine workshops were held, with themes related to Communication, Work and Production, Environment and Technology, and 2.148 people were trained, highlighting the participation of children, adolescents young people, adults and the elderly, as well as the mass participation of the rural population, predominantly female.

Keywords: Rondon project; University extension; Environment; Education; Communication.

\section{Resumen}

Declarado recientemente como Patrimonio Inmaterial de la Educación Superior brasileña, por el Proyecto de Ley $\mathrm{N}^{\circ}$ 4613 de 2019, el Proyecto Rondon, desarrollado por el Ministerio de Defensa, en colaboración con instituciones de educación superior (IES) estatales, municipales y públicas, su objetivo es contribuir a la formación de jóvenes universitarios como ciudadanos y al desarrollo sostenible en comunidades con poca asistencia. En este sentido, el presente trabajo reporta la experiencia de estudiantes y profesores de la Universidad de José do Rosário VellanoUNIFENAS, campus Alfenas, como resultado de la participación en la Operación Vale do Acre desarrollada entre el 8 y el 17 de julio de 2019, en la ciudad de Acrelândia-AC. Se llevaron a cabo veintinueve talleres, con temas relacionados con la comunicación, el trabajo y la producción, el medio ambiente y la tecnología, y se capacitó a 2.148 personas, destacando la participación de niños, adolescentes, jóvenes, adultos y ancianos, así como la participación masiva de la población rural, predominantemente femenino.

Palabras clave: Proyecto rondon; Extensión universitaria; Medio ambiente; Educación; Comunicación.

\section{Introdução}

A indissociabilidade entre ensino, pesquisa e extensão é decorrente de processos históricos iniciados a partir da demanda da sociedade por uma universidade mais comprometida com a construção de um mundo melhor, levando em consideração a realidade complexa dessa sociedade. Esta conquista social foi construída por diversos setores da sociedade e comunidade universitária em interlocução com o Poder Público (Xavier, 2019).

A Extensão Universitária é o processo educativo, cultural e científico que articula o Ensino e a Pesquisa de forma indissociável, viabilizando a relação transformadora entre a universidade e a sociedade. É uma via de mão dupla, com trânsito assegurado à comunidade acadêmica, que encontrará, na sociedade, a oportunidade de elaboração da práxis de um conhecimento acadêmico (Forproex, 2012). No retorno à Universidade, docentes e discentes trarão um aprendizado que, submetido à reflexão teórica, será acrescido àquele conhecimento. Esse fluxo que estabelece a troca de saberes sistematizados, acadêmico e popular, terá como consequência: a produção do conhecimento resultante do confronto com a realidade brasileira e regional; a democratização do conhecimento acadêmico e a participação efetiva da comunidade na atuação da Universidade. Além de instrumentalizadora desse processo dialético de teoria/prática, a Extensão é um trabalho interdisciplinar que favorece ao estudante de ensino superior a visão integrada do social (Forproex, 2006).

Dentre os projetos de extensão universitária de grande relevância nacional, surge o Projeto Rondon, cujo objetivo é desenvolver ações que tragam benefícios permanentes a municípios brasileiros em situação de vulnerabilidade, buscando a melhoria do bem-estar social e capacitação de multiplicação das temáticas abordadas. O Projeto Rondon, desenvolvido pelo Ministério da Defesa, encontra-se em tramitação o Projeto de Lei no 4613 de 2019 apresentado pelo senador Arns para que seja o "Projeto Rondon" declarado como Patrimônio Imaterial da Educação Superior Brasileira (Arns, 2019). Esse projeto em parceria com governos estaduais, municipais e Instituições de Ensino Superior (IES) públicas e privadas, tem como objetivo contribuir para a formação do jovem universitário como cidadão e o desenvolvimento sustentável em comunidades pouco assistidas.

Além disso, o Projeto Rondon, visa transmitir aos universitários participantes, o sentido de responsabilidade social e coletiva em prol da emancipação cidadã, do desenvolvimento e da defesa dos interesses nacionais contribuindo com a formação acadêmica por meio dos trabalhos desenvolvidos, proporcionando, além de um espaço de conhecimento da realidade brasileira, a interação com outras realidades, muitas vezes distante das que costumam presenciar, garantindo que haja uma 
valiosa troca de experiências entre comunidades, acadêmicos, militares, professores e gestores/governantes (Martinez et al., 2019).

Poder participar do projeto desde a elaboração da proposta pela Instituição de Ensino Superior (IES) à execução das atividades junto aos acadêmicos rondonistas selecionados, significa crescimento pessoal, concretização do que se define por papel da universidade na sociedade que corrobora para o desenvolvimento social. Audy (2017) ressalta que não se pode desconectar ciência, tecnologia, inovação e desenvolvimento, uma vez que elas se interagem de forma simultânea e complexa e não distante, as pessoas são apontadas como principal força propulsora desse ciclo, com isso pode-se dizer que se obtém o desenvolvimento como consequência ou mesmo produto final dessa interação.

Para a Operação Vale do Acre, a Instituição de Ensino Superior (IES) confiou a confecção e lapidação criteriosa das propostas que foram desenvolvidas do dia 08 ao dia 17 de julho de 2019 na cidade de Acrelândia-AC. A Universidade acredita que uma intervenção social, ainda que rápida seja a sua aplicação, se feita em locais cuja as pessoas estejam em situações de vulnerabilidades como o desemprego, moradia, desnutrição, violência, poluição, dentre outros determinantes sociais a partir de medidas simples, porém efetivas promovem melhorias na qualidade de vida de uma comunidade.

\section{Metodologia}

Trata-se de uma pesquisa-ação, de abordagem qualitativa para uma prática reflexiva com ênfase social. Assim, de forma indutiva com a pesquisa-ação os pesquisadores podem estar em contato direto com os fenômenos sociais para constatar suas particularidades e de forma participativa podem se envolver na resolução dos problemas em conjunto com outros atores envolvido no ambiente onde for aplicada (Pereira, Shitsuka, Parreira \& Shitsuka, 2018). As atividades executadas por meio de oficinas, foram elaboradas pelo núcleo de extensão e assuntos comunitários da Universidade José do Rosário Vellano (UNIFENAS), situada em Alfenas - Sul de Minas Gerais, tiveram por finalidade contribuir com a sustentabilidade do meio ambiente, comunicação, tecnologia, trabalho e produção, criteriosamente definidas.

As oficinas de trabalho são atividades elaboradas para serem desenvolvidas em grupos, e por meio dessas é possível coletar informações e ao mesmo tempo oferecer possibilidades de transformação (Andrade, 2009).

Estudo tem demonstrado que oficinas de trabalho são atividades estruturadas para serem executadas em grupos, o número de participantes não consiste em uma variável dependente, bem como o número de encontros, pois a proposta foca-se por uma questão central dentro de uma determinada realidade social e que a partir do processo de reflexão os participantes são envolvidos na totalidade para pensar, sentir e agir (Afonso, 2006).

Foram propostas a priori 19 oficinas, sendo três na área de comunicação: Xiringar (Oficina de gerenciamento das mídias sociais), Hora de Brechar (Oficina das apresentações), Gogó de sobra (Oficina de preparo a comunicação da comunidade); quatro na área de trabalho: Mapinguari (Oficina de sistemas orgânicos) - subdividida em três Módulos (Inseticidas naturais e armadilhas no combate as pragas no cultivo; Utilização adequada dos equipamentos de Proteção individual, Manuseio das embalagens de agrotóxicos e destino; Compostagem), O Lixo a favor da comunidade (Oficina de informação e reciclagem), Taboca e arte (Oficina de artesanato), Mãos na Terra (Oficina hortifrúti); três na área de meio ambiente: Besourão (Oficina para a construção de fossa séptica econômica), Rasga - Mortalha (Oficina conscientização do lixo hospitalar), Num-se-pode Desperdiçar (Oficina sobre conservação e higienização dos alimentos); quatro na área de tecnologia e produção: Caboré (Oficina para geração de energia solar), Guarda-chuva (Oficina para captação e reserva de agua da chuva), Aquaponia (Oficina que associa hortaliças e a piscicultura), Pé de Garrafa (Oficina para construção de sistema de irrigação sustentável); e cinco atividades complementares: Semeando (Oficina de artesanato), Concurso de gastronomia Master Chef, Ginástica Laboral - oficina para um público mais específico de um frigorífico, por considerar importante para o rendimento no trabalho com o intuito de melhorar o desempenho nas atividades laborais, reduzir sequelas relacionados a 
posturas e movimentos inadequados, Conscientização ambiental - Soltura dos Tracajás e Construção do Espaço Rondon.

A população foi convidada a participar nos dias correspondentes às atividades que foram previamente divulgadas em rádios do município, intensificada por grupo de whatsapp e abordagem direta em pontos comerciais que era parte da oficina de Comunicação.

Os grupos se reuniram em escolas municipais na área urbana e rural, espaço aberto (plantação para subsistência familiar e comercial) e em um auditório cedido pela prefeitura, assim, os acadêmicos se direcionaram para diferentes abordagens com a participação e envolvimento garantidos da comunidade. Os encontros aconteceram nos períodos matutino, vespertino e noturno de acordo com a proposta e o público alvo.

As oficinas foram desenvolvidas na sua totalidade e, sete delas foram realizadas por mais vezes, por solicitação da população e em locais diferentes, totalizando 29 oficinas ministradas em 10 dias, com um público geral de aproximadamente 2140 pessoas, desses destacamos a participação de crianças, adolescentes - jovens, adultos e idosos, destacamos ainda a participação maior foi atribuída a população rural, com predomínio do sexo feminino.

\section{Resultados e Discussão}

Para a operação Vale do Acre, as ações foram desenvolvidas tendo como público alvo gestores municipais, conselheiros e lideranças comunitárias, educadores de ensino fundamental e médio, agentes comunitários, adolescentes, além de terem sido desenvolvidas ações direcionadas para crianças e população em geral, tendo em vista a capacitação de pessoas para atuarem como multiplicadores dos temas abordados.

Para tal, foram utilizadas como estratégias para desenvolvimento das ações utilizou-se de oficinas, seminários, rodas de conversa, vídeos, grupos e dinâmicas individuais e coletivas. Em todas as atividades desenvolvidas foi levando em consideração a realidade do município, tendo sempre momentos para os participantes relatarem suas experiências.

$\mathrm{Na}$ área da comunicação, utilizamos de meios para a divulgação do Projeto na cidade, como duas rádios locais e grupo de divulgação whatsapp. Na oficina intitulada como "Hora de Brechar" foi feita a primeira abordagem e apresentação do projeto a comunidade, tendo a participação de 223 pessoas. Em oficina específica foi trabalhado a população participante: Agentes visitadoras - integrantes do Programa Criança Feliz; Agentes comunitárias saúde e funcionárias do CRAS a arte de se comunicarem, processar as informações em destaques e certificarem de sua veracidade antes de compartilhar e espalhar. Para essa atividade denominou-se de "Xiringar" que no vocabulário do Acre significa espalhar. Discutiram-se os meios de veiculação de notícias que podem ser verdadeiras ou falsas.

$\mathrm{Na}$ oficina "Gogó de sobra" teve como objetivo ouvir, informar e preparar a comunidade por meio de audiência pública, a fim de buscar opiniões, sugestões e soluções às demandas sociais. Dentre os temas abordados, foi discutido, em parceria com o SEBRAE, o passo a passo sobre a construção de cooperativas, destacando os desafios e benefícios para a população. Este tema foi de grande relevância uma vez que foi solicitado pela prefeitura local.

Através das oficinas de comunicação, foram capacitadas 282 pessoas, sendo 15 delas através da oficina "Xiringa", 44 pela oficina "Gogó de Sobra" e 223 pela oficina "Hora de Brechar", como representado na Figura 1. 
Figura 1 - Distribuição dos participantes nas oficinas de Comunicação.

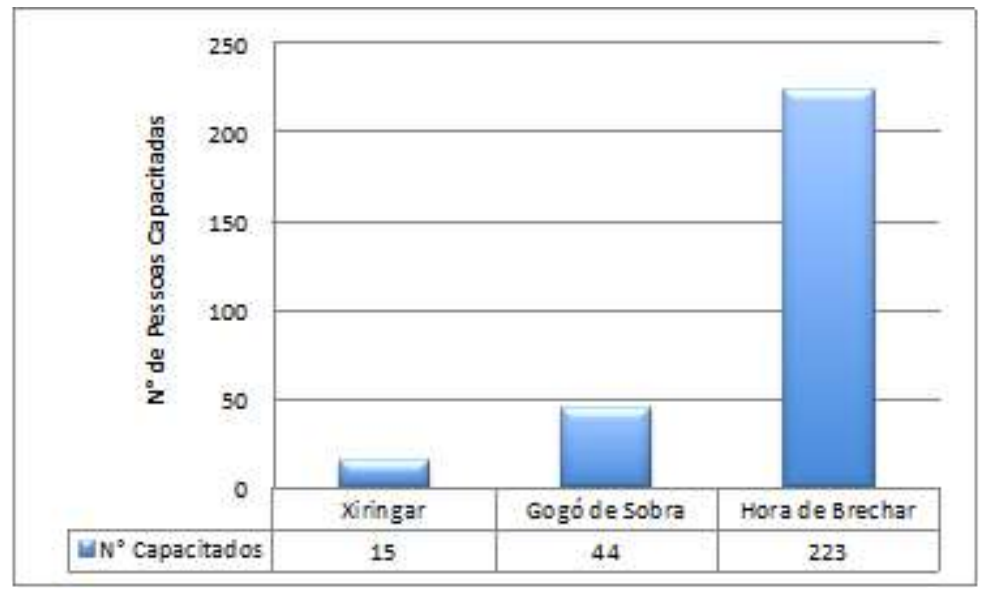

Fonte: Borges et al. (2019).

Com o objetivo de capacitar produtores locais, com especial atenção a agricultura familiar e sustentável; as oficinas voltadas ao trabalho tiveram como objetivo incentivar o cooperativismo, associativismo e empreendedorismo para a geração de renda e o desenvolvimento econômico sustentável. Ao todo foram capacitadas 584 pessoas dentre as quatro oficinas trabalhadas no município.

Visando reduzir o uso de agrotóxicos na agricultura e incentivar a utilização de inseticidas naturais e armadilhas para pragas no cultivo, a oficina "Mapiguari", contou com a participação da população em geral e na zona rural, resgatando os costumes praticados no campo por seus antepassados e que surtiam efeitos positivos sem prejuízos à saúde do produtor e consumidor. Foi apresentado passo a passo para confecção e instalação de armadilhas caseiras eficazes no combate de insetos da citricultura ("mosca das frutas") e da cafeicultura ("broca-do-café") (Brasil, 2001), assim como a preparação de adubos líquidos $100 \%$ orgânicos com eficiência comprovada, tendo exemplos como: Urina de vaca curtida e chorume de compostagem ou silagem. Na mesma oficina também foi feita a conscientização da população quanto ao uso de EPI's (Equipamentos de Proteção Individual) e descarte, manuseio correto de agrotóxicos.

Devido a crescente preocupação com o descarte incorreto de resíduos sólidos em todas as regiões brasileiras, a oficina "O lixo a favor da comunidade" mostrou que, se tratado de forma correta, o lixo pode gerar trabalho e renda para a comunidade. Através da oficina houve o incentivo a criação de uma cooperativa para a coleta e venda de materiais reciclados de forma adequada, gerando grande interesse da população local.

Para valorizar produtos locais, através da oficina "Taboca e Arte", foi demostrado a fabricação de artesanatos com bambu, fibra e ceda de bananeira, matérias-primas encontradas em grande quantidade na região, incentivando a população local a aumentar a renda familiar com a comercialização de tais produtos.

A oficina "Mãos na Terra" além de contribuir para melhoria nutricional das famílias do município, com a introdução de hábitos alimentares saudáveis, teve como objetivo promover a geração de renda da comunidade com a venda das hortaliças produzida nas hortas comunitárias. Tudo isso, utilizando de forma produtiva e criativa espaços urbanos ociosos. Além disso, tal ação estimulou a concepção de economia solidária, através de implantação de cooperativas para a gestão junto com o poder público.

Com as oficinas relacionadas ao Trabalho, foram capacitadas 584 pessoas, sendo 288 delas por meio da oficina "Mapiguari”, 210 pessoas pela oficina "O Lixo a Favor da Comunidade", 62 pessoas pela oficina "Taboca e Arte" e 24 pela oficina "Mãos na Terra" (Figura 2). 
Figura 2 - Distribuição dos participantes nas oficinas de Trabalho.

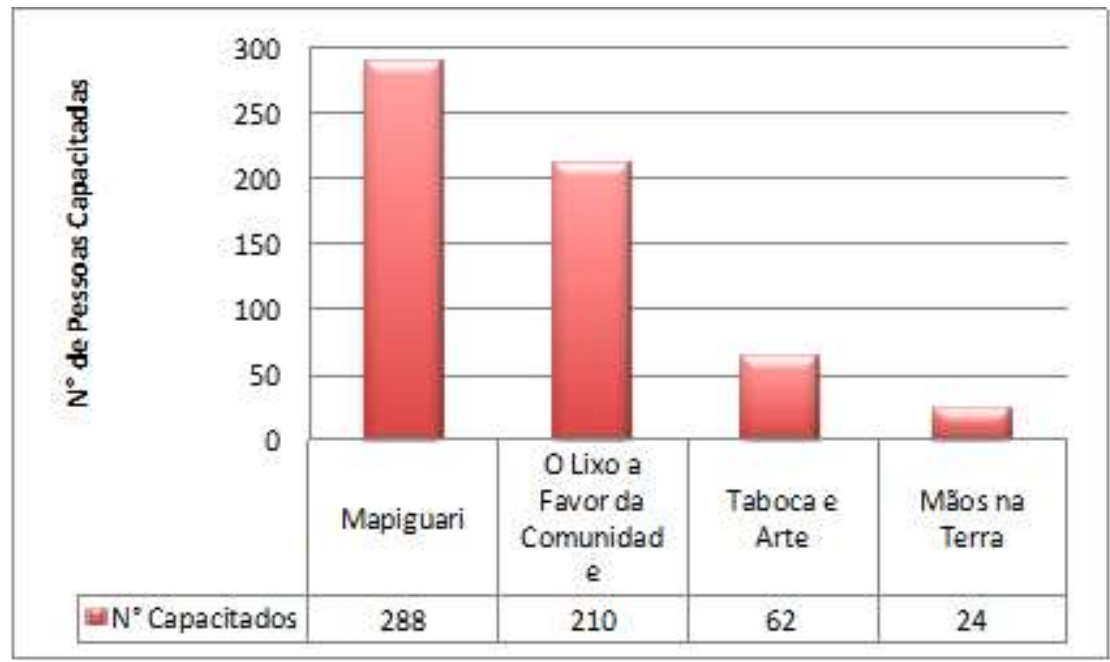

Fonte: Borges et al. (2019).

Devido a crescente preocupação com o meio ambiente e sua preservação, foram propostas três oficinas com âmbito ambiental a fim de capacitar, mobilizar e realizar campanhas na área de educação ambiental, particularmente no que se refere a saneamento: resíduos sólidos, esgotamento sanitário e água.

Apesar de o saneamento básico ser um direito assegurado pela Constituição Federal, cerca de 100 milhões de brasileiros não possuem coleta de esgoto. Tal fato amplia a desigualdade e impede a evolução econômica do Brasil, visto que o saneamento é umas das metas para serem atingidas pela Agenda 2030. Nesse contexto, a oficina intitulada como "Besourão" teve como objetivo capacitar os moradores para construção de uma fossa séptica biodigestora por evapotranspiração, um sistema de tratamento dos resíduos provenientes da descarga do vaso sanitário.

No Acre, apenas 12,2\% da população tem acesso à coleta e 19,4\% ao tratamento de esgoto, além disso, dos 22 municípios do estado, apenas cinco possuem medidas para o descarte de águas contaminadas. Assim, a construção da fossa por Evapotranspiração torna-se extremamente aplicável a realidade das comunidades locais por tratar-se de um mecanismo de descarte correto do esgoto sem gerar efluentes, poluição do solo, das águas superficiais e do lençol freático.

A oficina teve como público alvo representantes da comunidade, gestores, servidores públicos e pessoas interessadas em saneamento básico, saúde e meio ambiente. Após a divulgação atingimos como espectadores servidores municipais da construção civil e agentes de saúde.

$\mathrm{Na}$ execução da atividade inicialmente foi explicado os benefícios da solução em questão na prevenção de doenças, e em seguida foi apresentado o detalhamento da construção da fossa juntamente com um protótipo em pequena escala. Visando a geração de emprego e renda, também foi proposto um plano de negócios para a construção da fossa em escala comercial para trabalhadores que desejavam a complementação da renda familiar de forma autônoma ou em cooperativas.

Como desfecho, foi possível obter através desta oficina a conscientização dos cidadãos sobre a ligação direta do saneamento básico com a saúde e o desenvolvimento local, bem como a possiblidade de intervenções nos aspectos sanitários e econômicos de Acrelândia.

Neste mesmo contexto, outro assunto abordado na oficina intitulada como "Rasga Mortalha", foi sobre o gerenciamento correto dos resíduos oriundos de estabelecimentos prestadores de serviços de saúde, sendo de extrema importância para garantir a qualidade da saúde coletiva e a preservação do meio ambiente. Muitas vezes esse gerenciamento é negligenciado trazendo riscos às pessoas e ao meio ambiente. Dessa forma, essa atividade foi desenvolvida para repassar a comunidade local informações sobre o correto gerenciamento desses resíduos. 
Foi possível perceber durante a palestra que os ouvintes estavam cientes dos riscos, e já sabiam a maioria das informações passadas, porém, não era colocado em prática seus conhecimentos no assunto. Dos dados mais relevantes foram que $42,4 \%$ já se acidentaram com perfuro cortantes; $93,3 \%$ conhecem alguém que já se acidentou com perfuro cortantes; 75,7\% responderam que o destino dos RSS é o lixão; 54,5\% referem que a população se informa sobre os RSS (Resíduos de Serviço de Saúde) pelos agentes de saúde; 66,6\% responderam que a população descarta RSS em sacolas plásticas comuns; $66,6 \%$ responderam que a oficina foi excelente e $21 \%$ que a oficina superou as expectativas.

Na oficina "Num-se-pode desperdiçar" foi relatado a importância do aproveitamento integral dos alimentos, através da reutilização das sobras de alimentos produzidos para o consumo no dia a dia da população, contribuindo na diminuição de resíduos, melhorando a qualidade do meio ambiente e consequentes benefícios a saúde.

Por meio da oficina foi oferecido à comunidade conhecimentos de fatos, conceitos e ideias básicas sobre a importância do reaproveitamento dos alimentos, destacando o ganho nutricional na inserção destes alimentos na dieta da população para que a mesma possa ter acesso a produtos mais nutritivos e que não exijam mudanças de seus hábitos de consumo.

O número de pessoas impactadas nas oficinas relacionadas ao Meio Ambiente foram de 575, sendo 269 pessoas na oficina "Besourão", 49 pessoas na oficina "Rasga Mortalha” e 257 pessoas na oficina "Num-se-pode desperdiçar" (Figura 3).

Figura 3 - Distribuição dos participantes nas oficinas de Meio Ambiente.

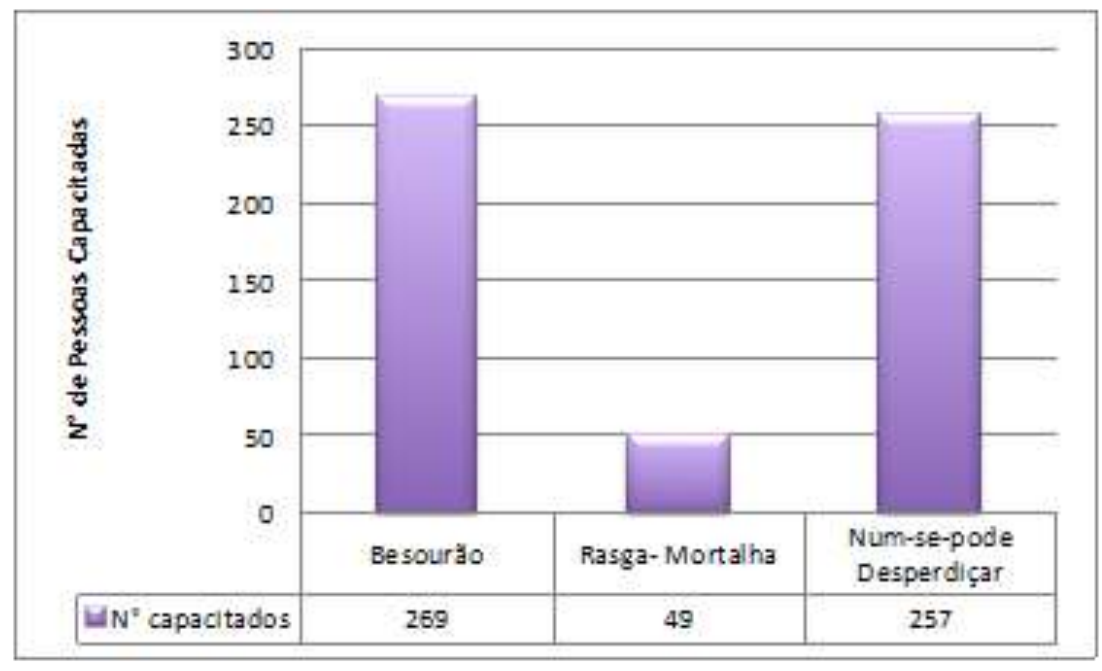

Fonte: Borges et al. (2019).

No cenário atual de escassez de recursos naturais que atinge diversas regiões do país, faz-se necessário a busca por técnicas autossustentáveis capazes de suprir a demanda por alimentos e promover a manutenção dos recursos naturais, promovendo uma melhor qualidade de vida da comunidade. Nesse contexto, as oficinas relacionadas a Tecnologia e Produção abordaram temas desde a captação de água da chuva a desenvolvimento de lâmpadas sustentáveis.

A oficina que foi denominada de "Guarda-chuva" trouxe para os participantes a consciência de que mesmo com chuva em abundância, o uso da água de forma consciente é questão de cidadania, pois na região em questão chove-se muito, porém há períodos do ano com escassez de água, então conhecer o método de captação de água com baixo custo, reduzindo seu consumo gera para o município desenvolvimento sustentável.

Após a palestra expositiva, onde foi relatado todos os benefícios da técnica de captação de água da chuva, os participantes tiveram a oportunidade de construir um reservatório utilizando materiais de baixo custo e de fácil obtenção, com o intuito de estimulá-los a replicar a técnica em suas residências. 
Neste mesmo sentido, a oficina "Pé de Garrafa" orientou moradores quanto a construção de um sistema de irrigação sustentável uma vez que a irrigação de pequenas propriedades rurais é uma necessidade constante, em especial para irrigação de hortaliças para consumo próprio ou comercialização local. Construído a partir de um mecanismo simples, foi utilizado canos, PET e válvulas de baixo custo, que foi instalado na horta comunitária deixado como legado para a cidade de Acrelândia.

Foi mostrado aos participantes que, com a ajuda da vazão do próprio sistema, a água é direcionada até as garrafas PET por meio da mangueira e saindo pelos furinhos feitos em sua superfície, pulverizando a água nos pontos onde se adaptou as garrafas. A oficina gerou estímulo aos participantes, que relataram a necessidade de replicar tal mecanismo em suas propriedades.

Visando um ganho econômico e a diminuição da dependência de energia elétrica, a ofícina "Caboré" propôs a implementação de uma lâmpada barata, reciclável e de fácil acesso a comunidade, sendo utilizada apenas uma garrafa PET para sua fabricação. Conhecida como lâmpada de Moser, tal proposta já forneceu iluminação para aproximadamente 11 mil pessoas nas cinco regiões do país, atingindo territórios que ainda vivem sem eletricidade. A tecnologia em questão não provoca impacto ambiental, tornando-se uma alternativa alinhada aos 17 Objetivos de Desenvolvimento Sustentável (ODS).

Durante a oficina, foi relatado aos participantes que a lâmpada só funciona durante o dia, uma vez que reflete e difunde a luz solar no ambiente interno, tendo grande utilidade em galpões, currais e ambientes onde há atividades diurnas. Com o intuído de mostrar sua fácil instalação, algumas lâmpadas de Moser foram instaladas na sala de artesanatos deixada como legado pelos participantes da equipe do Projeto Rondon.

Na oficina "Aquaponia" foi trabalhado a produção orgânica e sustentável de alimentos associado a criação de peixes. Tal ferramenta une em um só sistema, a hidroponia (cultivo de hortaliças em água) com a piscicultura (criação de peixes). O objetivo desta oficina foi capacitar a população para serem aptos a praticarem esta técnica de obtenção de alimentos, visto que ela pode reduzir o consumo de água em até $90 \%$, se comparada aos sistemas convencionais.

Como público alvo da oficina estabeleceu-se a população em geral, e durante a sua execução foi construído um modelo em escala real utilizando materiais totalmente recicláveis a fim de ressaltar a facilidade e o baixo custo de implantação do sistema. Em seguida, foram propostos modelos de lucratividade a serem obtidos com esta técnica e sugestões de quais hortaliças e peixes são adaptáveis para a criação na região.

Evidenciamos como impacto desta oficina a possibilidade de oferecer população meios de obtenção de alimentos de forma orgânica e sustentável aliando-se a geração renda complementar. Além disso, foi possível ensinar a utilização de materiais recicláveis de forma integral e sem custo, bem como o aproveitamento integral dos espaços domésticos.

Ao todo, como pode ser observado na Figura 4, foram capacitadas 53 pessoas, sendo 38 pela oficina "Guarda-Chuva", 4 pela oficina "Pé de Garrafa", 4 pessoas pela oficina "Caboré" e 7 pela oficina "Aquaponia". Quando comparado as outras temáticas, as oficinas relacionadas a Tecnologia e Produção teve um número baixo de pessoas capacitadas, tal fato é justificado pela carga horária extensa das oficinas, onde foram abordados conteúdos teóricos e práticos, fazendo com que diminuísse o número de participantes devido a indisponibilidade de tempo. 
Figura 4 - Distribuição dos participantes nas oficinas de Tecnologia e Produção.

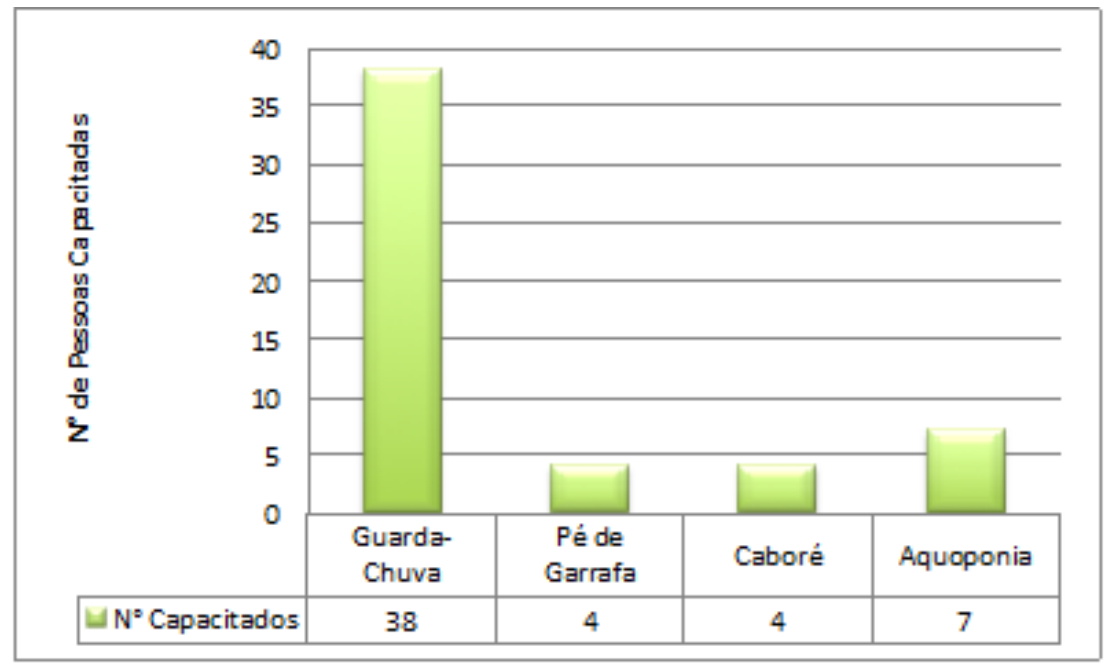

Fonte: Borges et al. (2019).

Com a finalidade de suprir as necessidades da comunidade onde a operação foi realizada, 5 oficinas complementares foram desenvolvidas ao longo dos 10 dias em que a equipe esteve na região, todas elas baseadas nas áreas temáticas do projeto proposto.

Observamos dificuldades reais enfrentadas pela população, mas também foi visível o comodismo em muitas pessoas com pouca ou nenhuma perspectiva de melhorias de vida, situação que as impedem de ver possibilidades de mudanças. As atividades desenvolvidas pelas equipes do Rondon buscam incentivar a população à mudança, porém para que alcançar os objetivos é necessário conseguir atingir a população e fazer com que eles participem dessas atividades. Dessa forma, a oficina "Semeando" buscou através do artesanato uma forma de aproximação com a comunidade local. Foi através dela que foram abordados assuntos com empoderamento feminino, violência contra a mulher, abuso sexual infantil, dentre outros. Depoimentos relatados pelos participantes deram a oportunidade para que os acadêmicos rondonistas colocassem em prática todos os conhecimentos e formas de abordagem recebidos dentro da universidade. Tal experiência foi de grande valia para todos os envolvidos.

No intuito de valorizar a culinária local, o concurso gastronômico intitulado como "MasterChef", incentivou a população a participar com a confecção de comidas típicas regionais, mostrando a eles que os diferentes tipos de temperos e sabores fazem parte da nossa identidade nacional, o que torna o nosso país rico e multicultural.

Ressaltamos aqui a identidade cultural gastronômica do Estado do Acre que é mediada por sua colonização e fortemente norteada pelos costumes indígenas, assim, a gastronomia acreana é marcada por produtos naturais e peculiares, como frutas, caças, peixes e outros itens regionais (Quinzani \& Capovilla, 2015).

A pedido do proprietário, alunos rondonistas dos cursos de saúde, realizaram junto aos funcionários de um frigorífico a oficina de "Ginástica Laboral". Foi destacado diversos benefícios da atividade, como: melhora do sistema cardíaco, respiratório e esquelético; aumento da consciência corporal, prevenção de doenças ocupacionais; minimização da fadiga, esgotamento e monotonia. As intervenções foram feitas entre 10 a 15 minutos, baseada em técnicas de alongamento, respiração, percepção corporal, reeducação postural e compensação dos músculos, com essa oficina foi possível capacitar os funcionários dessa empresa para a auto ginástica, reduzindo os impactos de atitudes corporais erradas e prejudiciais a saúde, externalizando ao baixo rendimento no trabalho.

A ginástica laboral (GL) é fornecida de livre vontade para os funcionários. São aplicações variadas e planejadas, para que o funcionário possa fazer pausas no serviço, como atividades e exercícios físicos. A ginástica laboral trabalha partes do 
corpo como cérebro, estimula o autoconhecimento, podendo ampliar a consciência, e autoestima, além de proporcionar a recuperação e/ou manter a capacidade de movimentos naturais que as pessoas venham a ter, oferece melhores condições de vida, saúde e lazer (Mendes, Leite, 2014).

Por meio do projeto SOS Quelônios (Ibama, 2016), foi realizada a oficina “Conscientização Ambiental”, onde os acadêmicos rondonistas puderam participar da soltura de filhotes de Tracajás, às margens do Rio Abunã, afluente do Rio Madeira, que se localiza o seringal Porto Dias, na divisa entre a Bolívia e o Brasil. O projeto tem como objetivo preservar a espécie, existente na região Norte do país, e sensibilizar comunidades sobre a importância das causas ambientais. Tal ação mostra que as pessoas da comunidade estão ainda mais envolvidas na proteção dos tracajás, já que o projeto conta com a consciência dos moradores em proteger os locais de desova e não incentivar a caça.

Como legado para a população de Acrelândia e finalização do projeto, foi construído pela população, acadêmicos e professores Rondonistas, o “Espaço Rondon”. O espaço foi construído em um local público, cedido pela prefeitura, e está aberto a comunidade em geral. Ele conta com uma brinquedoteca, galpão para oficinas de artesanato e uma horta comunitária. Tal espaço foi criado devido a necessidade de um ambiente de interação e recreação para a população, além de ser um local para ser colocado em prática todos os ensinamentos deixados ao longo dos 10 dias de operação.

Com as oficinas complementares, foram capacitadas 654 pessoas, sendo 454 na oficina "Semeando", 3 pessoas na oficina "MasterChef”, 32 pessoas na oficina de "Ginástica Laboral”, 93 pessoas na oficina de "Conscientização Ambiental” e 72 pessoas no "Espaço Rondon", como mostra a Figura 5.

Figura 5 - Distribuição dos participantes por oficinas Complementares.

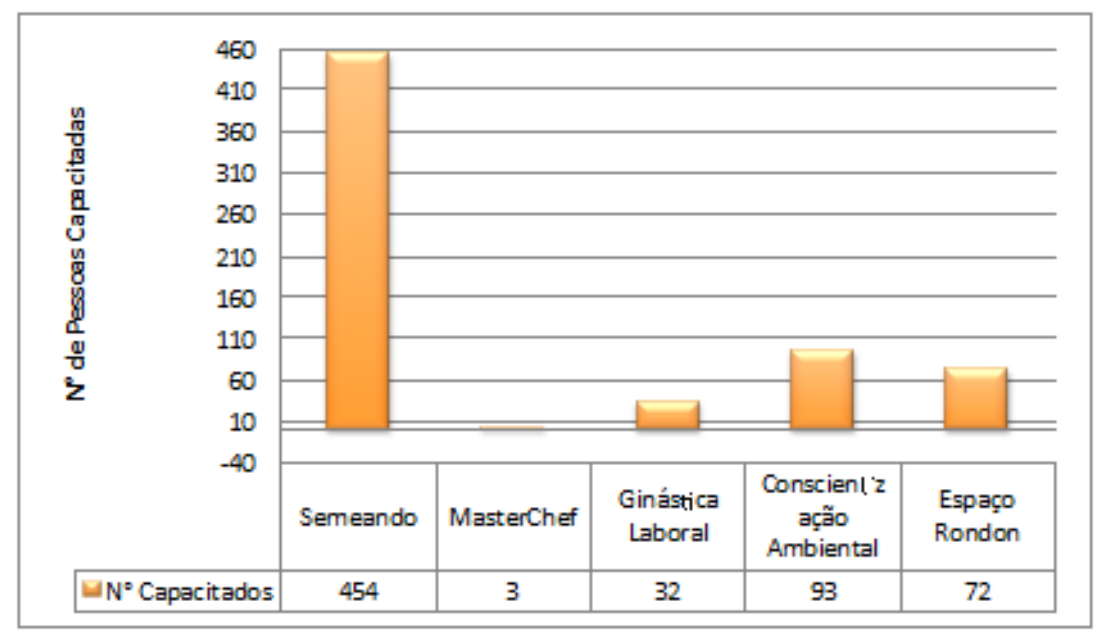

Fonte: Borges et al. (2019).

Como pode ser observado na Tabela 1, ao longo dos dez dias de operação, foram capacitadas 2.148 pessoas, sendo as oficinas Complementares as que tiveram maior adesão pela população, com a capacitação de 654 pessoas, equivalente a $30,4 \%$ do total de participantes. Esta alta adesão pode ser atribuída ao fato de que as oficinas foram realizadas durante o final de semana em que estivemos no município e que uma delas, a de Ginástica Laboral, foi realizada no local de trabalho dos participantes, viabilizando a capacitação de um maior número de pessoas.

As oficinas relacionadas as áreas de Trabalho e Meio Ambiente atingiram média de 27,2\% e 26,8\%, respectivamente, quando comprada com o público geral. O número total de capacitados nas duas temáticas foi de 1.159 pessoas, equivalente a $54 \%$ do número total de participantes. O alto índice de pessoas capacitadas nas duas oficinas está relacionado aos temas abordados, uma vez que estes assuntos estão diretamente ligados ao dia-a-dia da população acrelandense, principalmente aos 
da zona rural. Outro fator que contribuiu para este elevado índice foi a maneira em que os temas foram apresentados, sendo em sua grande parte em formas de palestras, rodas de conversas e seminários, o que possibilitou reunir um maior número de pessoas por oficina.

As oficinas na área de Comunicação capacitaram 282 pessoas, número equivalente a 13,1\% do total de participantes. Uma vez que as oficinas foram utilizadas como meio de apresentação e divulgação do projeto, tendo sido realizadas nos primeiros dias de operação, seu número de pessoas impactadas foi menor que as citadas anteriormente, mas foram de grande importância para a realização e desenvolvimento de todas as ações propostas.

Com menor índice de capacitados, totalizando 58 pessoas, as oficinas nas áreas de Tecnologia e Produção trouxeram propostas inovadoras para a comunidade, que para sua execução demandou tempo para exposição de conteúdos teóricos e práticos, fazendo com que houvesse a diminuição do público em geral, uma vez que as oficinas foram oferecidas nos períodos diurnos e durante a semana.

Vale ressaltar que todas as oficinas geraram certificados aos participantes com carga horária referente ao tempo de desenvolvimento de cada proposta.

Tabela 1 - Número de pessoas capacitadas no Município de Acrelândia- Operação vale do Acre (julho de 2019).

\begin{tabular}{|c|c|c|}
\hline TEMÁTICAS & N CAPACITADOS & PORCENTAGEM \\
\hline Comunicação & 282 & $13,1 \%$ \\
\hline Trabalho & 584 & $27,2 \%$ \\
\hline Meio Ambiente & 575 & $26,8 \%$ \\
\hline Tecnologia e Produção & 53 & $2,5 \%$ \\
\hline Complementares & 654 & $30,4 \%$ \\
\hline TOTAL & $\mathbf{2 . 1 4 8}$ & $\mathbf{1 0 0} \%$ \\
\hline
\end{tabular}

Fonte: Borges et al. (2019).

Na Figura 6 é possível identificar as atividades feitas em oficinas com um público cuja idade é diversificada, bem como o ambiente em essas foram efetuadas contemplando assim as necessidades da comunidade e contribuindo para a formação de multiplicadores de conhecimento prático. Na letra A mostra a Solenidade de Abertura do Projeto com a presença de autoridades locais e crianças do ensino fundamental, já na B corresponde ao dia atribuído para Demonstração de confecção e funcionamento do sistema de Aquaponia, na $\mathrm{C}$ atendendo a uma solicitação de um frigorífico foi ministrado Técnicas de Alongamento na oficina de Ginástica Laboral, na D em visita ao CRAS, discutiu-se sobre Violência contra as Mulheres, fenômeno naturalizado na sociedade e que impede o empoderamento da mulher na sociedade.

Por essa abordagem foi possível constatar que tal fenômeno apresenta diferentes facetas, assim para atingir a meta de redução da violência doméstica contra a mulher e o seu empoderamento proposta na ODS 5 (Igualdade de Gênero) da Agenda 2030 é preciso políticas que vão além de proteção a vítimas, pois estudos mostram que a dependência financeira de alguns cônjuges, bem como a presença de crianças no relacionamento, em idades mais jovens, dentre outros fatores são fatores que acabam por manter a mulher em situação de violência doméstica e isso por não ter perspectiva de melhorias e falta de oportunidades no mercado de trabalho (Tauchen, Witte, 1995).

Na letra E para estímulo e propagação das informações apresentadas foram dispensados aos participantes certificados 
ao término de cada oficina, na F pela Oficina na área de Comunicação foi apresentada formas de se comunicar e o poder dessa na comunidade.

Figura 6 - Atividades desenvolvidas com a população residente em Acrelândia-AC em julho de 2019.
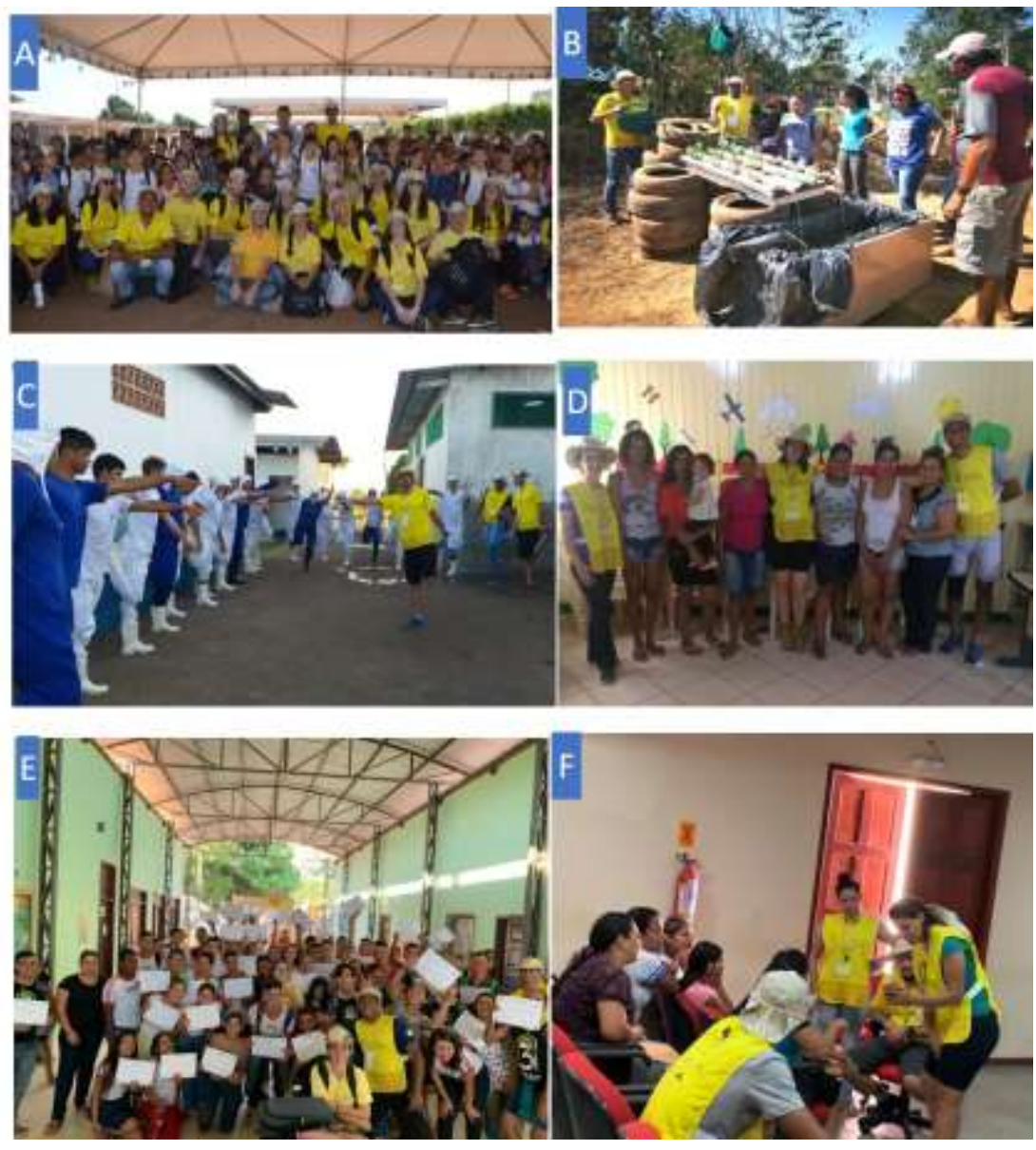

Fonte: Borges et al. (2019).

Como parte das atividades na letra $\mathrm{G}$ profissionais da saúde e agentes comunitários de saúde foram contemplados por meio da Oficina Rasga-Mortalha, momento em que se discutiu sobre descarte correto de materiais biológicos e perfuro cortantes para reduzir os acidentes de trabalhos e sobretudo contaminação por agentes biológicos, na letra H moradores da zona rural do município foram contemplados por oficinas desenvolvidas em escola municipal, assim como os funcionários das mesmas puderam participar, na letra I é possível identificar as atividades com artesanatos o que possibilitou reunir diferentes gerações e compartilhar de ensinamentos, já na letra J foi discutido e ensinado técnicas não tóxicas para erradicação de insetos e pragas nas plantações bem como construção de armadilha natural e finalizou se as atividades deixando no município uma proposta de continuidade das ações como aproveitamento de um terreno municipal por meio da Finalização do Espaço Rondon letra K. (Figura 7). 
Figura 7 - Atividades desenvolvidas com a população residentes zona rural e Finalização com o Espaço Rondon em Acrelândia-AC em julho de 2019.

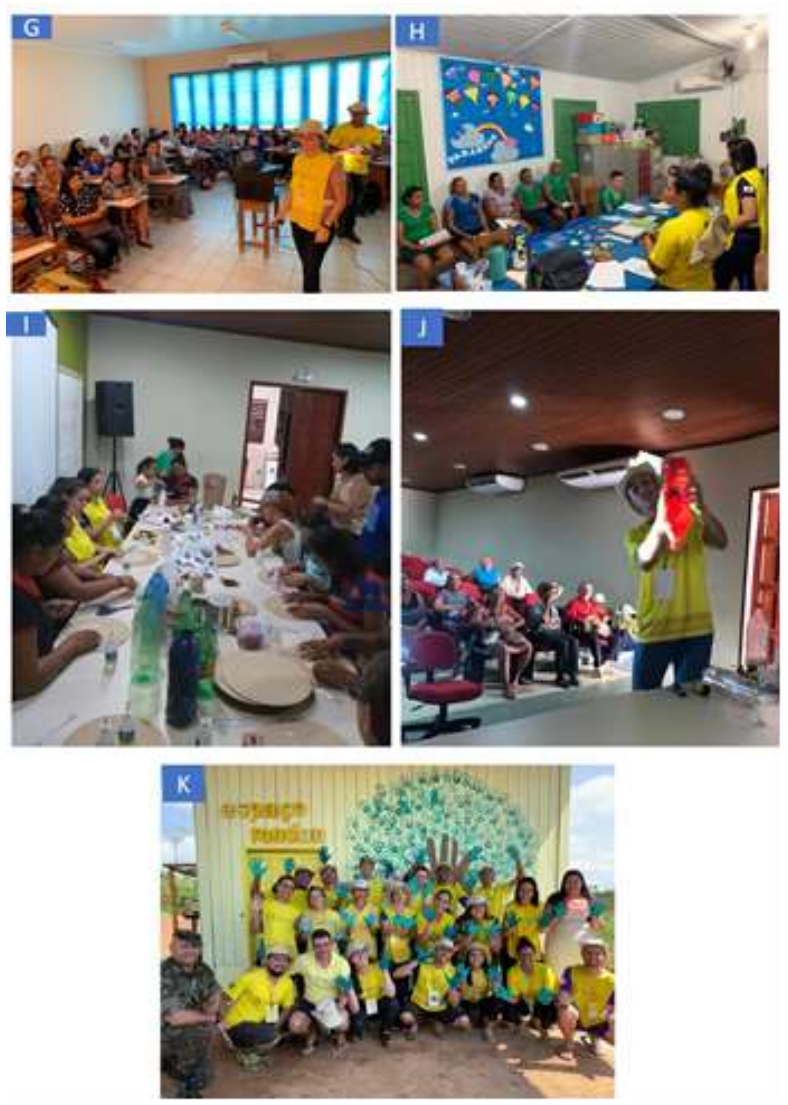

Fonte: Borges et al. (2019).

Nos dias correspondentes a execução das atividades verifica-se pelas figuras 6 e 7 o envolvimento dos acadêmicos com a população. Essa aproximação e troca de experiências leva ao aprendizado de ambos os lados, para os acadêmicos a responsabilidade social e cidadania. Franco, Bahia, Silveira, Carvalho (2020) discutem sobre a importância de os universitários participarem desses projetos extensionistas, uma vez que com essas experiências extra muros da universidade contribui para a formação de um profissional com responsabilidade social e cidadania com caráter autônomo, sensível e comprometido com a realidade em que se insere.

Em relação aos moradores, essas atividades contribuem para novas perspectivas de um fazer acontecer dentro de suas realidades utilizando a matéria-prima fornecida pela natureza e colocando em prática suas habilidades técnicas e artísticas para uma visão empreendedora. Com o espaço Rondon deixado para a comunidade de forma simbólica é um despertar para a necessidade de se criar espaços de convivências para idosos, crianças e adolescentes, com isso as perspectivas aumentariam e o desejo por sair para grandes centros não se justificaria.

\section{Considerações Finais}

Todas as atividades desenvolvidas durante a operação Vale do Acre foram adaptadas ao meio e ao público com os quais a equipe se deparou. Na prática foi possível observar e constatar as habilidades e atitudes de cada membro da equipe na reestruturação das atividades, quando o participante não era exatamente aquele que se esperava. Com isso, destacou-se a grandeza na transcendência de seus conhecimentos e papel humanístico na contribuição para melhorias da comunidade assistida. 
Esses acadêmicos foram capazes de materializar o conceito de inovação nas concepções de uma universidade. Pois inovar, partindo de um conhecimento previamente pronto foi necessário. Das propostas que tinham em mãos, transformaram o local ao seu redor, agregando valores humanísticos, de cidadania, econômico, social e pessoal. Desafios enfrentaram sem que se deixassem suprimir pelo desânimo e cansaço.

Consideramos de fundamental importância que trabalhos que envolvam a sustentabilidade, trabalho, meio ambiente, comunicação, bem como, a educação, a saúde, direitos sociais venham a ser cada vez mais desenvolvidos não apenas para comunidades que estejam distantes dos grandes centros e sim para a totalidade, pois problemas encontrados em regiões distantes estão gritando em nosso meio e urgem de ações concretas. Ainda que existem diversos trabalhos que convergem para essa proposta, os pesquisadores devem torná-los públicos e de conhecimento científico o que pode contribuir para elaboração de políticas sociais mais efetivas e coletivas, com maior investimento para atividades nessas áreas.

Destarte, desenvolver projetos que convergem para essas áreas poderão não apenas reduzir o desemprego, fome, mas contribuirão para um futuro melhor às novas gerações, com isso considerando o foco desse estudo propomos pensarmos em projetos que visem o despertar para o empreendedorismo a partir do que se dispõe de matéria - prima e de habilidades desenvolvidas sem impactar de forma negativa o meio ambiente com poluentes e destruição desenfreada da flora e fauna, para tal é preciso mobilizar toda a sociedade e não apenas as áreas afins.

\section{Agradecimentos}

Ao Ministério da Defesa, à Universidade José do Rosário Vellano (UNIFENAS) - Alfenas/MG, à prefeitura do município de Acrelândia e ao Projeto Rondon, por todo apoio prestado, sendo fundamentais para a execução da Operação Vale do Acre.

\section{Referências}

Afonso, M. L. M. (2006). Oficinas em dinâmica de grupo: um método de intervenção psicossocial. Casa do Psicólogo, 9 - 63.

Andrade, C. J. M. (2009). As equipes de saúde da família e a violência doméstica contra a mulher: um olhar de gênero. Tese (Doutorado)/2009 - Programa Interunidades de Doutoramento em Enfermagem da Escola de Enfermagem da Universidade de São Paulo, São Paulo, 139p.

Audy, J. (2017). A inovação, o desenvolvimento e o papel da Universidade, Estudos Avançados, 31 (90).

Arns, F. J. (2019). "Projeto Rondon" Patrimônio Imaterial da Educação Superior Brasileira - Projeto de Lei no 4613 de 2019.

Brasil. Ministério da Agricultura (2001). Empresa Brasileira de Pesquisa Agropecuária Centro Nacional de Pesquisa de Monitoramento e Avaliação de Impacto Ambiental. Armadilha para monitoramento de insetos. https://ainfo.cnptia.embrapa.br/digital/bitstream/CNPMA/5817/1/armadilha_insetos.pdf.

Forproex. Fórum de Pró-Reitores de Extensão das Instituições de Educação Superior Brasileiras (2012). Política Nacional de Extensão Universitária.

Forproex. Fórum de Pró-Reitores de Extensão as Instituições de Educação Superior Brasileiras (2006). O Plano Nacional de Extensão Universitária. Porto Alegre: UFRGS; Brasília: MEC/SESu. http://www.renex.org.br/documentos/Colecao-Extensao-Universitaria/01-Plano-Nacional-Extensao/Plano-nacional-deextensao-universitaria-editado.pdf.

Franco E. C. D., Bahia F. C. S., Silveira E. A. A., \& Carvalho G. D (2020). Repercussões do programa de extensão ACOLHER na formação de estudantes extensionistas. Research, Society and Development, 9(10), e3749108676. https://doi.org/10.33448/rsd-v9i10.8676.

Hundley G. C., \& Navarro R. D (2013). Aquaponia: a integração entre piscicultura e a hidroponia. Revista Brasileira de Agropecuária Sustentável, 3(2).

Ibama (2016). Instituto Brasileiro do Meio Ambiente e dos Recursos Naturais Renováveis Manejo conservacionista e monitoramento populacional de quelônios Amazônicos. Brasília.

Martinez A. C., Santos D. F., Lombardo Y. L. D., \& Moraes M. F (2019). Ações da Equipe Unioeste no Piauí Durante o Projeto Rondon - Operação Parnaíba/2019, Seurs- Extensão e Inovação, 1 - 6.

Mendes A. R., Leite N. L (2014). Ginástica laboral: princípios e aplicações práticas. Manole.

Pereira A. S., Shitsuka D. M., Parreira F. J., \& Shitsuka R. (2018). Metodologia da pesquisa científica. UAB/NTE/UFSM. https://repositorio.ufsm.br/bitstream/handle/1/15824/Lic_Computacao_Metodologia-Pesquisa-Cientifica.pdf?sequence=1 
Research, Society and Development, v. 10, n. 1, e43210111930, 2021

(CC BY 4.0) | ISSN 2525-3409 | DOI: http://dx.doi.org/10.33448/rsd-v10i1.11930

Quinzani S. S. P., \& Capovilla V. M (2015). A identidade da cultura gastronômica acreana. Contextos da Alimentação - Revista de Comportamento, Cultura e Sociedade, 3(2). Centro Universitário Senac.

São Paulo. Instituto Trata Brasil - ITB. (2017). Painel Saneamento Brasil. https://www.painelsaneamento.org.br.

Tauchen H., Witte D (1995). “The Dynamics of Domestic Violence.”American Economic Review, 85(2), 414 - 418.

Xavier S. M. G (2019). Extensão universitária: retrospecto histórico do período 1951-2018 na Universidade de Sorocaba, Brazilian Journal of Development, Curitiba, 5(6), 7138 - 7154. 